\title{
Role of Women in The Sustainable Management of Indigenous Woodlands in Marange Communal Lands
}

${ }^{1}$ Chikwature $\mathrm{E},{ }^{2}$ Chikwature W

\author{
${ }^{1}$ St Josephs High School Box 3050 Paulington, ${ }^{2}$ Mutare, Mutare Polytechnic Box 640, Mutare
}

emiliachikwatureec@gmail.com,whatmorec@gmail.com

\begin{abstract}
This research study sought to determine the role of women in the sustainable management of indigenous woodlands in Manicaland province using Marange communal lands as a point of reference. In this study three traditional leaders, three women's groups and seventy community women were used as research subjects. Questionnaires were used to gather data from the local women from the three selected villages. Interviews were also used to collect information from traditional leaders and women's group leaders. These interviews were important in complementing data collected through questionnaires. Field observations were also carried out to enrich the data collected through interviews and questionnaires. The study showed that while women played a vital role in the sustainable management of indigenous woodlands in Marange communal lands, they faced various constraints including greater workload at home with little time to pursue activities outside the family. Therefore the study recommends that since women are more intimately involved with the environment through their day to day activities like fuel wood collection, they should be given due recognition in decision making processes. Finally, it is also recommended that the land tenure system should be redesigned to cater for female heads of households.
\end{abstract}

Keywords: woodlands, resource conservation, sustainable development, environmental management

\subsection{Introduction}

Rural communities the world over have been utilizing indigenous woodlands resources for millennia. Today human activities have intensified and population has increased. This has led to household fuel wood scarcity, affecting women and their families. Time allocation studies of women's work have illuminated with frightening clarity the hours and days spent collecting combustible material for the preparation of food. Loss of forest resources that were sources of fibres, edible fruits, medicines and other goods, due to deforestation, has not only directly affected household livelihoods, but has also adversely affected small scale rural and household industries. Much attention therefore has to be paid to maintaining forest resources and using them in a sustainable manner, (Women Feature Service, 1992).

Natural resource management programmes have expanded rapidly in the last two decades responding to regional fuel, fodder and water scarcities, soil degradation and to decline in soil cover in Zimbabwe and other third world countries. Women are frequently identified as direct beneficiaries and participants of these natural resources management programmes. They have and are still playing a significant role in environmental management programmes and sustainable development, promoting training efforts and organizing themselves at local, national and international levels (ibid). Therefore, this research is an investigation into the role of women in the sustainable management of indigenous woodlands. This is because women participation in woodland resource management is becoming a critical strategy for environmental sustainability worldwide.

\subsection{Materials and Methods}

The design employed was a descriptive survey method. During the descriptive research, the researcher did not manipulate variables or control the environment in which the study took place. The purpose was to systematically describe the facts and characteristics of the given phenomena, population or area of interest, in this case, Marange Communal Lands. The research design is the grand plan for enhancing the researcher's 
internal and external validity. The central focus of the descriptive survey method is to examine facts about people, their opinions and attitudes. Its purpose is to draw attention to the degree to which events of the phenomena in question are related. This research design was chosen because since it does not only enhance internal and external validity but it also has an exploratory nature whereby additional variables maybe discovered that shed new light upon the phenomena in question, in this case, the role of women in the sustainable management of indigenous woodlands in Marange Communal Lands. The design also allowed the researcher to study relationships or even events as they happen in a real life situation. It enhanced reliability of collected data and was relatively easier to administer and it minimized the possibility of interviewer bias.

The sampling procedure used was the simple random sampling. Randomization is defined by Creswell (2013) as the assignment of objects of a universe to subsets of the universe in such a way that every member of the universe has an equal probability to be chosen for assignment. It is one common strategy used in selecting and assigning participants to groups for study.

The village headmen for Shundure, Ngomasha and Chinyawenge villages were asked to provide information on the number of households in their respective villages. The combined household population of these villages was 350 (Table 3:1). This was then used as a sampling frame to select twenty percent of the households. Random sampling was done in each village since they had different population sizes. The researcher used random sampling because each unit had an equal chance of being selected and it reduced the problem of labeling. Table 3.1 shows sampling frame and the sample size.

Table 1: Sampling Frame and Sample Size for Households in Marange Communal Lands

\begin{tabular}{|l|l|l|l|}
\hline Village & No. of Households & $\%$ & Sample Size \\
\hline Shundure & 130 & 20 & 26 \\
Ngomasha & 100 & 20 & 20 \\
Chinyawenge & 120 & 20 & 24 \\
\hline Total & 350 & 20 & 70 \\
\hline
\end{tabular}

Source: Headmen's village household lists

Twenty percent of the target population yielded a sample of 70 households where all the respondents would be women. These were the respondents who were involved in the questionnaire survey.

Apart from the seventy women other subjects used in the study included traditional leaders, the Mutare Rural District Council and three women's groups. These important informants had appropriate knowledge on the location and the role of women in the sustainable management of indigenous woodlands in Marange Communal Lands. The Mutare Rural District Council provided a topographical map for the area. The women's groups who were interviewed were the Kubatana Women's group in Ngomasha village, Pamberi Women's group in Chinyawenge village and Kushinga Women's group in Shundure village. Four pupils at Shundure Secondary school were used as research assistants in the distribution and administering of questionnaires.

\subsection{Results and Discussion}

\subsection{Background of Respondents}


Table 2 Age Groups of Respondents

\begin{tabular}{|l|c|c|}
\hline Age group & No. of respondents & $\%$ \\
\hline $16-25$ & 15 & 21 \\
$26-35$ & 25 & 36 \\
$36-45$ & 20 & 10 \\
$46-55$ & 7 & 4 \\
$56-65$ & 0 & 0 \\
$>65$ & 70 & 100 \\
\hline Total & 3 & \\
\hline
\end{tabular}

Source: Questionnaire Survey

It can be deduced that all age groups were present at the time of visit. Women are the ones working closely with indigenous woodlands and had to give clearly their perceptions about their participation in the sustainable management of indigenous woodlands. The number of respondents above 55 years of age was very low. Most of the respondents were middle aged. This means that most women in Marange Communal Lands are of the active working age group, that is $16-64$ years and they contribute much to the country's development. This is because these women are running the households while most of their male counterparts are working in towns, commercial farms and mines for wages.

Table 3 Marital status of respondents

\begin{tabular}{|l|c|c|}
\hline Marital Status & No. of Respondents & $\%$ \\
\hline Single & 7 & 10 \\
Married & 40 & 21 \\
Widowed & 15 & 9 \\
Divorced & 6 & 3 \\
Separated & 2 & 100 \\
\hline Total & 70 & \\
\hline
\end{tabular}

Source: Questionnaire Survey

The results confirmed that most respondents are married. This means that they have to cater for their families and at the same time do environmental management activities outside the family. This, according to Sweetman (1997) is one of the constraints to women participation in environmental management. This is because greater workload at home results in less time for pursuing activities outside the family. The $43 \%$ of the widowed, single, divorced and separated have an implication on the ownership of land. The customary land tenure system prevents women from owning land, according to the studies of Whitlow (1997). This means that these respondents do not own land of their own. 
Table 4. Educational level

\begin{tabular}{|l|c|c|}
\hline Level & No. of Respondents & $\%$ \\
\hline None & 3 & 4 \\
Primary & 15 & 21 \\
ZJC & 18 & 43 \\
'O' Level & 30 & 6 \\
'A' Level & 4 & 0 \\
Degreed & 0 & 0 \\
Other & 0 & 100 \\
\hline Total & 70 & \\
\hline
\end{tabular}

Source: Questionnaire Survey

From the results, most respondents have received secondary education. This means that they have some knowledge about environmental management and indigenous woodland conservation techniques as this is part of the educational syllabi. This also is an advantage to the community since illiteracy in women has trapped generations in a cycle of poverty and environmental degradation, as observed by Williams, et al (1994) in their studies.

Table 5. Length of stay

\begin{tabular}{|l|c|c|}
\hline No. of years & No. of Respondents & $\%$ \\
\hline $1-10$ years & 17 & 24 \\
$11-20$ years & 25 & 36 \\
$21-30$ years & 25 & 36 \\
$>30$ years & 3 & 4 \\
\hline Total & 70 & 100 \\
\hline
\end{tabular}

Source: Questionnaire Survey

On length of stay it was clear that most of them stayed for more than a year in Marange Communal Lands. This means that they have experienced fuel wood scarcity problems in area and are playing a role in trying to maintain the few types of woodland left. This also means that this respondence now takes woodlands and other resources in the area as part of their own property. Overally, the whole respondents' profile provided a good ground for analysis of the role of women in the sustainable management of indigenous woodlands in Marange Communal Lands. 


\subsection{Role of women in the sustainable management of indigenous woodlands.}

The results confirmed the notion that women play a crucial role in the sustainable management of indigenous woodlands since they all agreed that women play a crucial role in the sustainable management of indigenous woodlands. Since the respondents were women who use fuel wood in their day to day cooking and warming, they felt it was crucial for them to be involved in the sustainable management of indigenous woodlands within their locality. This will enable future generations to benefit from these woodlands.

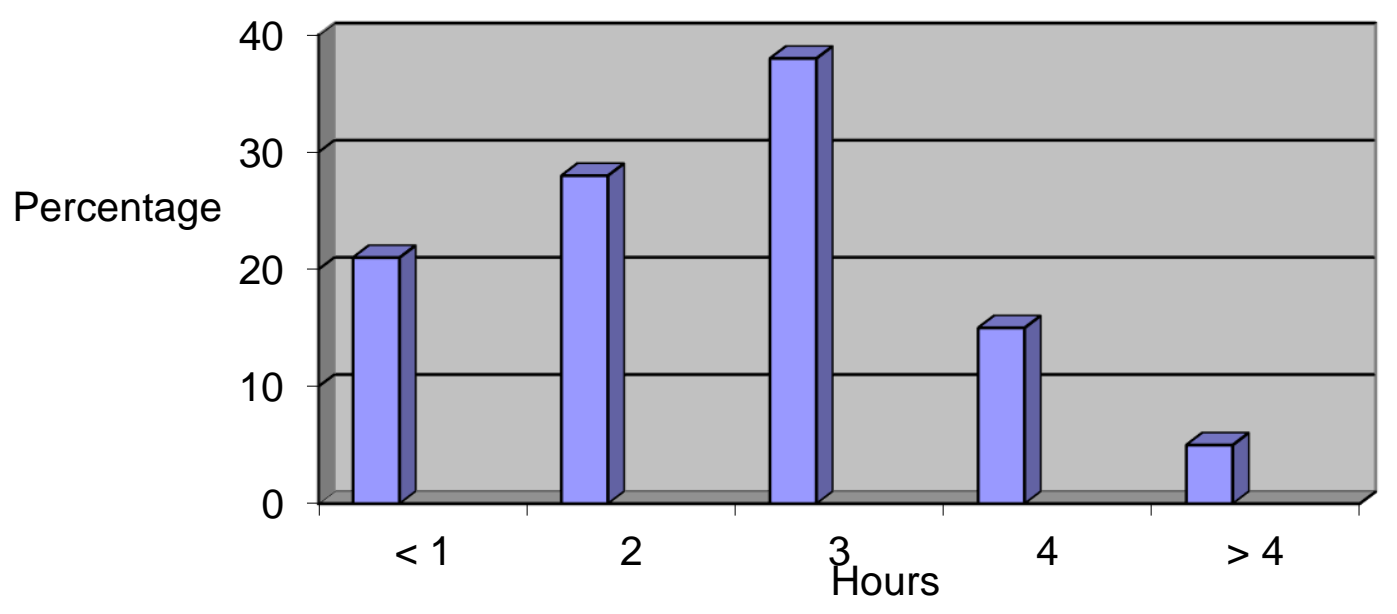

Figure 1: Time spent fetching fuel wood per day

Source: Questionnaire Survey

On assessing the time spent fetching fuel wood per day, the results indicated that they spend less than one hour. This may be because they have their private woodlots near their homesteads. Those who spend more than one hour probably have to travel several kilometers in search of fuel wood, since the surrounding places are deforested either for fuel wood or for agricultural purposes. The respondents were asked about measures they are employing to reduce fuel wood consumption in their households. Table 4.3 shows the results.

Table 6: Measures to reduce the amount of fuel wood consumed including:

(i) Use of fuel efficient tsotso stove

(ii) Use of alternative sources of fuel

\begin{tabular}{|l|l|l|}
\hline Variable & No. of Respondents & $\%$ \\
\hline All of the above & 50 & 72 \\
None of the above & 2 & 3 \\
(i) only & 8 & 11 \\
(ii) only & 10 & 14 \\
Other & 0 & 0 \\
\hline Total & 70 & 100 \\
\hline
\end{tabular}

Source: Questionnaire Survey 
The results confirmed the argument that women employ various methods to reduce the amount of fuel wood consumption in their households. The $3 \%$ who indicated that they do not use any method cited reasons like lack of money and most of them probably do not own any piece of land in accordance to the land tenure system, as observed by Whitlow (1997). So they saw no point in conserving wood in areas they do not own. When asked whether the measures were successful in reducing fuel wood consumption, the following were the results.

Table 7: Successes of the measures employed to reduce fuel wood consumption.

\begin{tabular}{|l|l|l|}
\hline Loads per month & No. of Respondents & $\%$ \\
\hline 2 loads & 15 & 21 \\
1 load & 50 & 72 \\
$<1$ load & 5 & 7 \\
\hline Total & 70 & 100 \\
\hline
\end{tabular}

Source: Questionnaire Survey

Ninety-seven percent indicated that the measures were successful and revealed that they were reduced to two loads or below per month. The three percent who indicated that the measures were not successful were those who did not use any method to reduce the amount of fuel wood consumed in their households.

Respondents were also asked whether they were involved in the sustainable management of indigenous woodlands. The following results were obtained.

Table 8: Involvement of women in the sustainable management of indigenous woodlands in the following activities:

(i) Planting tree seedlings on public land.

(ii) Practicing agro-forestry on individual farms

(iii)Involved in seed collection campaigns in schools and churches

\begin{tabular}{|l|l|l|}
\hline Activities & No. of Respondents & $\%$ \\
\hline All the above & 40 & 57 \\
None of the above & 2 & 3 \\
(iv) only & 5 & 14 \\
(v) and (i) only & 10 & 4 \\
(vi) only & 3 & 7 \\
(vii) and (iii) only & 5 & 1 \\
(viii) & 1 & 6 \\
\hline (i) and (iii) only & 4 & 100 \\
\hline Total & 70 & 7 \\
\hline
\end{tabular}

Source: Questionnaire Survey

Responses indicated that they are actively involved. This means that most respondents were aware of the importance of indigenous woodlands in their livelihoods. Most of them indicated that they plant tree 
seedlings on public land, practice agro-forestry on individual farms and involved in seed collection campaigns in schools and churches. They have formed various women's groups including the Kubatana, Pamberi and Kushinga women's groups. This clearly supports the ideas of Sweetman (1997) who observed that over a period of time women realized that they had to organize themselves separately in order for their concerns to be addressed. The three percent who indicated that they were not involved cited problems of old age and being prevented from participating by their male counterparts.

\subsection{Constraints to women participation in environmental management}

Respondents were also asked whether they have any constraints to fully participate in environmental management. The following results were obtained.

Table 4.8: Constraints to women participation in environmental management including:

(i) Greater workload at home resulting in less time for pursuing activities outside the family.

(ii) The dissolution of customary land tenure system which prevents women from owning land.

(iii) Cultural beliefs and practices which undermine the idea that women are full citizens of the states in which they live.

\begin{tabular}{|c|l|l|}
\hline Constraints & No. of Respondents & $\%$ \\
\hline All the above & 20 & 29 \\
None of the above & 0 & 0 \\
(i) only & 3 & 29 \\
(i) and (ii) only & 20 & 7 \\
(i) only & 5 & 21 \\
(i) and (iii) only & 15 & 1 \\
(i) only & 1 & 9 \\
(i) and (iii) only & 6 & 0 \\
\hline Other & 0 & 100 \\
\hline Total & 70 & \\
\hline
\end{tabular}

Source: Questionnaire Survey

The majority indicated that they faced a lot of constraints which include greater workload at home resulting in less time for pursuing activities outside the family. Another limitation cited was dissolution of customary land tenure systems which prevents women from owning land. In addition cultural beliefs and practices which undermine women's full citizenship rights in the state in which they live, was given as another constraint. Some also added the idea that they have fewer opportunities than men to attend school and that they are looked down upon by their male counterparts. This also supports the works of Williams et al (1994), Whitlow (1997) and Sweetman (1997) who observed that many legal obstacles exist which prevent women from fully participating in, and benefiting from, development and resource conservation despite the international legal conventions and agreements to ensure women's equal rights with men in spheres of activity. Very few cited old age as another constraint.

Respondents were also asked to suggest solutions to their constraints. The majority cited the need to revise the system of tenure so that they can have access to land, as well as the need to educate men on the 
importance of women involvement in the environmental management of resources. Some even suggested the idea of women empowerment so that they can express themselves confidently.

\subsection{Role of government and non-governmental organizations in the sustainable management of indigenous woodlands.}

Respondents were also asked whether they work with non-governmental organizations. Most of them cited the CADEC which they said provided seeds which are planted in herbal gardens. The main purpose of these herbal gardens was to reduce the cutting down of trees for medicinal purposes. This also supports Sweetman (2004) who suggested that non-governmental organizations often provide the only platform for women's public participation and promoting social change.

On the question of effectiveness, most respondents indicated that CADEC is effective since the herbal gardens are now in use. Ten percent who indicated that CADEC is not effective may be those who belong to religious sects that do not value the use of traditional medicines such as the Apostles (Vapostori).

The government agencies such as Environmental Management Agency and the Mutare Rural District Council are also working in the area with the help of traditional leaders. This also supports the ideas of Sweetman (1997) who observed that women, with help of government and non-governmental organization have made an attempt to have environmental law introduced as a subject in schools and colleges in many countries including Sri Lanka. From the results, Mutare Rural District Council is the one mostly known by the community. They conduct meetings pertaining to environmental management of natural resources. They also educate the community about forestry laws as well as putting penalties on offenders. These penalties are administered by traditional leaders. The money they get from fines is used largely for the purchasing of exotic wood seedlings especially of the eucalyptus. The $14 \%$ who responded that the government agencies are not playing a role in the management of indigenous woodlands in Marange Communal lands maybe those who do not attend meetings or who do not know that traditional leaders carry out certain tasks on behalf of these government agencies.

Field observations were made on 29 September 2018. The researcher visited Ngomasha, Chinyawenge and Shundure villages. Woodlands were found on public and private land. Herbal gardens were also found in each village which were administered by CADEC, a non-governmental organization.

On the issue of penalties, all the respondents revealed that a US $\$ 10.00$ fine was paid by offenders.

\section{Conclusions}

From the study it can be concluded that women in Marange Communal Lands are playing an active role in the sustainable management of indigenous woodlands. This supports the ideas from Women Feature Service (1992) which revealed that women are part of most environmental campaigns. They are planting tree seedlings especially of the eucalyptus exotic species on public land as well as practicing agro-forestry on individual farms. The results also supports Sweetman (1997)'s ideas that some women encouraged students to gather and study local herbs and encouraged some schools to grow medical herbs in gardens. In Marange Communal Lands medical herb gardens are scattered which are under the control of women with the help of CADEC. This also supports Sweetman (2004)'s ideas that NGOs often provide the platform for women's public participation and promoting social change. Government agencies such as Mutare Rural District Council and The Environmental Management Agency are also helping women through traditional leaders. Despite the wonderful work being done by women in Marange Communal Lands many legal obstacles exist which prevent them from fully participating in resource conservation. These constraints matched those observed by Williams et al (1994), Whitlow (1997) and Sweetman (1997)'s studies. 


\section{Recommendations}

Due to the important role that women have to play in the sustainable management of indigenous woodlands it is necessary to ensure that women involved get the required support such as facilitating development of appropriate structures and institutions at local level for indigenous woodlands resource management.

$>$ There is need to develop gender sensitive training materials in community forestry and distribute this to universities, training institutes and Non-Governmental Organizations for use in training programmes. These materials should be translated into local languages to ensure improved accessibility for rural women and men.

- Gender sensitive guidelines should be developed on the measures to reduce fuel wood consumption at household level.

> Guidelines should also be developed to assist extension planners and designers to meet the needs of women more effectively and incorporate gender into forestry curricula in education and training organizations.

- Men should stop being worried about their place in the household and community as they still hold their places. They should not feel inferior to women but should help them instead of keeping them down. This can be promoted by governments and other agencies through assigning economic value to women's labour in and outside their households.

There is need to redress the customary land tenure system so that women have access to land and other forms of income producing property. This is because many families due to HIV/AIDS are female headed. They should have equal rights with men to own land or livestock. This will enable women to invest time and resources in long term land improvements and embarking on environmental conservation projects.

Women should always have equal opportunity with men to attend school to reduce the cycle of illiteracy, poverty and land degradation. This would also enable them to empower themselves.

> Decision making should always be encouraged to promote empowerment of women. Responsible authorities should also embark on an educational campaign to educate local communities on laws and regulations that govern the use of indigenous woodlands in Marange Communal Lands.

\section{References}

1. Creswell J.W. (2013) Qualitative Enquiry Research Design. (3 ${ }^{\text {rd }}$ edition) UK: SAGE Publications Ltd

2. Gender, Society and Development: Natural Resources Management and Gender: A global Source Book (2002). Netherlands: Kit Publishers.

3. Mashingaidze, I.C. (1998) Poverty and the Environment: The Case of the Communal Areas in Zimbabwe. Mazvikade. Hotel: SOEPROZ.

4. Sweetman, Caroline (1997) Gender in Development Organizations' UK: Oxfam.

5. Sweetman, Caroline (ed) (2004) Gender, Development and Citizenship, UK: Oxfam

6. The Power to Change (1992) A Report by the Women's feature Service. India: Kali for Women.

7. Williams, Suzanne; Seed, Janet and Mwau Adelina (1994) The Oxfam Gender Training Mannual UK: Oxfam.

8. Whitlow, J. R. (1997) Deforestation in Zimbabwe: Some problems and prospects. Harare: N.R.B. 